\title{
Concepções sobre Cinética Química: a influência da Temperatura e da Superfície de Contato
}

Pamela Franco Marani pamela.franco.marani@.gmail.com http://orcid.org/0000-0001-8409-4996 Maringá, Paraná, Brasil

Thaís Andressa Lopes de Oliveira thais arievilo@hotmail.com http://orcid.org/0000-0002-4862-1258 Universidade Estadual de Maringá (UEM), Maringá, Paraná, Brasil

Marilde Beatriz Zorzi Sá

mari.zorzi@hotmail.com

Universidade Estadual de Maringá (UEM), Maringá, Paraná, Brasil

\section{RESUMO}

Identificar as concepções dos estudantes é fundamental para o processo de ensino e aprendizagem, pois ao conhecê-las é possível planejar e organizar as atividades a serem desenvolvidas com os estudantes. Visto isso, apresenta-se aqui parte dos resultados de uma pesquisa que objetivou analisar as concepções de estudantes do Ensino Médio sobre os fatores que alteram a velocidade das reações químicas, discutindo especificamente as concepções a respeito da influência da superfície de contato e da temperatura. A pesquisa foi realizada com 26 estudantes do segundo ano do ensino médio de uma escola pública paranaense. Os dados foram coletados por meio de diário de campo do pesquisador e de questionários, referentes à realização de um experimento, e analisados segundo a Análise de Conteúdo de Bardin. As respostas foram agrupadas em oito categorias, que revelaram descrições empíricas, em que foi possível observar que os estudantes apresentam dificuldade em relacionar a prática observada no experimento com o conteúdo aprendido em sala de aula, além de evidenciar dificuldades de argumentação e escrita. Tornou-se evidente a aprendizagem mecânica, que leva os estudantes a memorizarem os fatores que alteram a velocidade das reações sem que haja uma verdadeira compreensão do conteúdo, visto que a maioria deles apresentou dificuldades em relacionar energia cinética e colisões efetivas, e em justificar a influência da superfície de contato. Frente ao exposto, evidenciase a importância de se conhecer as dificuldades dos estudantes, pois a partir desse reconhecimento é possível traçar estratégias didáticas adequadas para melhoria da aprendizagem de conceitos de Química.

PALAVRAS-CHAVE: Concepções alternativas. Ensino de Química. Superfície de Contato. Temperatura. 


\section{INTRODUÇÃO}

O ensino de química ainda é visto por muitos educadores e pesquisadores como um desafio frente a intensidade de abstração que seus conceitos exigem. Se para os professores fazer a transposição didática dos conceitos exige reflexão quanto as estratégias de ensino que serão utilizadas, para os alunos a construção e compreensão desses conceitos só será possível se tais estratégias possibilitarem uma evolução gradual de tais conceitos.

Dessa forma, práticas de ensino tradicionais, nas quais prevalecem a ideia de ensino baseado meramente na transmissão e recepção dos conteúdos, não possibilitam ao aluno aprender e, ainda, ocasionam a construção e manutenção de concepções inadequadas sobre os conteúdos estudados (BEHRENS, 2013).

Enfatizando essa ideia, em ambientes de ensino tradicionais, muitas vezes, não são proporcionados momentos dialógicos nos quais os alunos podem expressar suas opiniões e dúvidas sobre a aula ou o ambiente ao seu redor. Tal postura é muito prejudicial, posto que ao inibir a participação dos alunos nas aulas, o professor acaba por limitar suas estratégias de ensino a mera memorização do conteúdo, perdendo-se importantes momentos de discussão coletivos, nos quais poderiam ser identificadas as concepções dos alunos sobre determinado assunto.

Para Mendes e Cardoso (2009), a percepção e a análise das concepções prévias e/ou alternativas dos estudantes são importantes para uma aprendizagem significativa, visto que possibilitam ao professor pensar em estratégias de ensino que possam problematizar tais concepções em um processo de investigação coletivo em sala de aula.

Dentro dessa perspectiva, Lima et al. (2000) apontam que o ensino de muitos conceitos químicos, como é o caso da cinética química, tem sido ministrado de forma expositiva, sem que sejam levado em conta os conhecimentos prévios e/ou o cotidiano dos alunos. Tal forma de ensino valoriza somente o discurso do professor, e gera uma desmotivação no aluno para a execução das tarefas propostas, já que estas, em geral, não possuem relação direta com sua vivência.

Além disso, um ensino desses conteúdos dado de forma desfragmentada e descontextualizada pode ocasionar uma má interpretação dos alunos sobre os fatores que alterariam a velocidade das reações, gerando concepções alternativas sobre eles ou reforçando concepções pré-existentes.

\section{AS CONCEPÇÕES ALTERNATIVAS E SUA INFLUÊNCIA NA APRENDIZAGEM}

O interesse pelos conhecimentos que os estudantes trazem para a sala de aula na área de Ensino de Ciências começou, aproximadamente, entre as décadas de 1970 e 1980, quando surgiram as primeiras pesquisas em educação a respeito dos conhecimentos prévios dos estudantes (SCHNETZLER, 2004, GOMES, 2008). Desde então, houve diversos estudos sobre as concepções dos estudantes que diferem dos conceitos científicos de algum modo, e há uma larga literatura a respeito, mostrando que existem padrões de pensamentos sobre determinados fenômenos da natureza.

As concepções alternativas, ou seja, as ideias que se distanciam do conhecimento científico, e que são originadas no processo de escolarização ou no 
contato cotidiano com um conceito, muitas vezes são resistentes e acabam por "persistirem após anos de instrução, sendo encontradas, inclusive, entre professores em situação de ensino" (GOMES, 2008, p. 15).

Ao perceber a relevância do tema, entende-se o motivo do surgimento do movimento das concepções alternativas, chamado assim pelos pesquisadores pelo aumento no número de trabalhos e pesquisas relacionados ao tema, as quais visavam ressaltar a importância de conhecê-las, investigar quais as concepções dos estudantes a respeito de diversos fenômenos, entre outras. De acordo com Schnetzler (2004),

[...] cerca de 4.000 pesquisas sobre domínios conceituais específicos foram realizadas nos anos 80 , constituindo o que se denomina "movimento das concepções alternativas". Essas investigações nos revelam, por exemplo, que os alunos compreendem as transformações químicas como justaposição de substâncias e não como interação de partículas que as constituem; que, no equilíbrio, as concentrações de reagentes e produtos precisam ser iguais; $e$ que uma barra de metal dilata porque seus átomos dilatam, já que os estudantes tendem a associar propriedades macroscópicas a entidades microscópicas (SCHNETZLER, 2004, p. 51).

A expressão concepções alternativas sugere, apesar de algumas controvérsias no significado do termo entre os pesquisadores da área (PEREIRA, 2017), que os estudantes seguem uma lógica para chegarem a essas ideias. Diferentemente de termos como concepções errôneas, ou ideias inadequadas, que apenas categorizam esse conhecimento como equivocado, descartando-o. Identificar quais são essas concepções, ou as ideias que fazem o aluno chegar a elas, é uma maneira de compreender o fracasso escolar, conhecendo os padrões de pensamento dos alunos, possibilitando a construção de estratégias e meios para melhoria do ensino de ciências e assim oportunizar para os estudantes interpretar os conceitos teóricos e fenômenos (GOMES, 2008).

Portanto, é imprescindível para o professor reconhecer que os estudantes não são "tábula rasa", ou seja, um ser desprovido do saber, pois o mesmo traz consigo conhecimentos oriundos de suas experiências, cultura, e concepções provenientes da escola, por esse motivo é importante que o professor esteja consciente de tais conhecimentos, para que o estudante alcance êxito na aprendizagem dos saberes científicos (SCHNETZLER; ARAGÃO, 1992, SCHNETZLER, 2004, HÜLSENDEGER, 2009).

Afinal, para os estudantes,

[...] suas concepções prévias ou alternativas fazem sentido, e por esse motivo são muitas vezes tão resistentes à mudança que comprometem a aprendizagem das ideias ensinadas, além de determinarem o entendimento $e$ desenvolvimento das atividades apresentadas em aula (SCHNETZLER, 1995, $p$. 27).

Em outras palavras, os conhecimentos que os estudantes levam para dentro da sala de aula são significativos para eles, o que justifica a dificuldade em resignificar determinados conceitos. Além disso, esses conhecimentos podem interferir na aprendizagem dos conceitos científicos. Segundo Lopes (1996), é de extrema importância que os professores reconheçam tanto as concepções prévias dos alunos quanto suas concepções ao longo do processo educativo, para que possam identificar e problematizar possíveis obstáculos para a aprendizagem. 
Assim, reforça-se que o conhecimento não é algo que se adquire, mas sim que se constrói gradualmente e que aborda, e muitas vezes desafia, as concepções dos estudantes em atividades educativas bem elaboradas, permitindo que os mesmos possam construir ou reconstruir suas teorias, construindo uma aprendizagem significativa. O construtivismo para Ausubel et al. (1991, apud GIORGI; CONCARI; POZZO, 2005), consiste em oportunizar ao aluno "aprender a aprender", por meio do que já sabe, ou seja, seu conhecimento preexistente.

A construção de conceitos é progressiva, de modo que os conhecimentos são resignificados de forma a tornarem-se cada vez mais consistentes (MOREIRA, 2016). O autor fala ainda da importância de propiciar avaliações que possam identificar se a aprendizagem ocorreu da forma esperada, ou seja, que evidencie compreensão de modo significativo. Dessa forma, durante a avaliação dos estudantes é necessário evitar somente a verificação de respostas certas, pois muitas vezes elas podem ser originárias de aprendizagem mecânica.

Ao discutir sobre as concepções alternativas, e assumir que estas são conhecimentos do aluno que possuem significado para ele, percebe-se a importância de valorizar essas ideias e discutir como elas interferem no processo de aprendizagem. Neste caso, discutiremos sobre elas com base na teoria da aprendizagem significativa que trata, justamente, da influência de conhecimentos preexistentes na construção e resignificação progressiva do conhecimento (MOREIRA, 2016).

De acordo com Moreira (2003), a aprendizagem significativa ocorre quando o estudante compreende o significado de um conceito, sendo capaz de argumentar sobre situações que o envolvam e, ainda, explicar o fenômeno segundo suas próprias palavras.

Segundo Ausubel e Novak (1980, apud MOREIRA, 2003), a aprendizagem significativa depende da interação entre as novas informações e as antigas já presentes na estrutura cognitiva do sujeito. Estas últimas constituem "[...] o mais importante fator para a transformação dos significados lógicos, potencialmente significativos, dos materiais de aprendizagem em significados psicológicos" (MOREIRA, 2003, p. 02). O autor evidencia ainda a importância da linguagem no processo de aprendizagem, junto à interação entre os conhecimentos já existentes na estrutura cognitiva e os novos. Pode-se inferir, portanto, que se torna imprescindível para a prática docente reconhecer os conhecimentos do estudante sem descartá-los apenas porque são diferentes do saber científico.

\section{FUNDAMENTOS TEÓRICOS E OBJETIVOS DO TRABALHO}

Como evidenciado por Zappe e Sauerwein (2016), que fizeram uma revisão bibliográfica sobre as pesquisas com o tema ensino de Cinética Química nos periódicos nacionais, nota-se que não há um número elevado de pesquisas neste tema. Segundo os autores, até 2016 apenas 2\% dos trabalhos publicados pela revista Química Nova na Escola se referiam à cinética química, de um total de 564 artigos.

A respeito do tema podem-se encontrar trabalhos sobre cinética química com diferentes enfoques, como trabalhos que apresentam propostas de material didático e/ou textos para serem utilizados em sala de aula, com abordagem 
conceitual (ROCHA-FILHO, 1999; CHAGAS, 2001), além de análise de livros didáticos (MARTONARO; MARCONDES, 2009; CIRINO; SOUZA, 2010).

Cirino e Souza (2010) mostram, em sua análise de livros didáticos, que o conteúdo de cinética química muitas vezes é abordado de forma superficial ou sem contextualização e/ou relação com outros conteúdos, o que pode gerar concepções inadequadas a respeito do tema. A hipótese levantada pelos autores é de que muitos professores utilizam o livro didático como único meio para preparar suas aulas, o que pode ser um atenuante na perpetuação de concepções alternativas.

Muitos trabalhos apresentam pesquisas realizadas sobre propostas de ensino e de atividades experimentais (TEÓFILO; BRAATHEN; RUBINGER, 2002; COSTA et al., 2006; MERÇON; GUIMARÃES; MAINER, 2011; VAZ; ASSIS; CODARO, 2011; VENQUIARUTO et al., 2011).

A respeito de investigação em sala de aula, pode se salientar os trabalhos que investigaram a influência das concepções alternativas, evolução conceitual (JUSTI; RUAS, 1997), ou de que maneira os estudantes se apropriam das teorias (CIRINO et al., 2009) e ainda, discussões a respeito da influência da contextualização no ensino de cinética química (LIMA et al., 2000;).

Pesquisas a respeito das concepções alternativas e prévias dos estudantes são necessárias no sentido de possibilitarem a construção de um alicerce teórico e metodológico para futuras investigações e, principalmente, para o aprimoramento de estratégias de ensino. Afinal, conhecendo os padrões e concepções mais comuns entre os estudantes, é possível traçar estratégias para superá-las.

De acordo com estes pressupostos, o presente trabalho busca conhecer as concepções alternativas de estudantes do segundo ano do ensino médio a respeito dos fatores que alteram a velocidade das reações químicas. Buscamos perceber se a aprendizagem do conteúdo se deu de forma mecânica ou não, por meio de análise das explicações dos estudantes a respeito dos motivos que fazem a temperatura e a superfície de contato alterar a velocidade das reações.

De forma mais explícita, a pesquisa buscou responder ao seguinte questionamento: Quais as concepções dos estudantes do ensino médio a respeito da influência da temperatura e da superfície de contato na velocidade das reações?

Espera-se que as discussões aqui apresentadas contribuam para a compreensão da importância de se levantar as ideias prévias, e concepções em geral, apresentadas pelos alunos sobre um determinado assunto, de forma a contribuir para o processo de ensino e aprendizagem, além de promover a conscientização da importância do diálogo e da problematização das concepções dos alunos para o ensino de química.

\section{PERCURSO METODOLÓGICO}

A pesquisa em questão foi feita junto a 26 estudantes do segundo ano do Ensino Médio de um colégio estadual da cidade de Maringá-PR. Foi realizada por uma acadêmica cursante da disciplina de Estágio Supervisionado, momento que a estagiária obteve oportunidade de vivenciar o cotidiano escolar, acompanhar as 
ações didáticas dos professores de Química e desenvolver atividades de regência nas turmas onde a pesquisa foi desenvolvida.

Para o desenvolvimento da pesquisa, os sujeitos participaram de uma atividade experimental. Essa atividade tinha como objetivo verificar se os estudantes haviam construído conhecimentos significativos acerca dos fatores que influenciam a velocidade das reações químicas, assunto abordado anteriormente pela professora regente da turma.

Assim, os instrumentos de coleta de dados foram as observações realizadas durante a atividade experimental, o diário de aulas da pesquisadora e as questões respondidas pelos estudantes.

\section{ETAPAS DESENVOLVIDAS}

Para responder a esses questionamentos e para a realização da atividade experimental, foram seguidos os seguintes passos:

a) Etapa 1: Questionário anterior à prática

Inicialmente, foi solicitado aos estudantes que respondessem a seguinte questão:

No experimento iremos submeter a mesma reação a condições experimentais diferentes, e assim poder observar quais fatores podem alterar a velocidade de uma reação. Quais são estes possíveis fatores? Justifique a influência de pelo menos um dos fatores.

Como já citado antes, os estudantes já haviam estudado o conteúdo em aulas anteriores com a professora regente da turma, e esta solicitou à estagiária que realizasse um experimento com o tema Cinética Química. Foi escolhido, então, um experimento que pudesse proporcionar aos alunos observar, de fato, essas mudanças e tirá-las do plano da abstração. Para tanto, foi feita a pergunta número um, que buscou identificar o que os estudantes compreendiam a respeito do conteúdo e, além disso, se eram capazes de argumentar sobre.

b) Etapa 2: Realização do experimento

A realização do experimento se deu em três etapas, segundo o roteiro apresentado no Quadro 01. A etapa número um consistia na apresentação do modelo de experimento aos estudantes, e posteriormente, da reação química envolvida, que consiste basicamente na reação do comprimido efervescente de vitamina C (comercial) com a água: Ácido ascórbico mais água, originando dióxido de carbono.

Após esta discussão seguiu-se com as demais etapas do experimento. A turma foi dividida em quatro grupos, no laboratório de Química da escola, onde cada grupo ficou responsável por realizar uma etapa do experimento, demonstrando para os demais. Ao final de cada etapa, a estagiária buscava discutir sobre o que ocorreu na reação, e o porquê. Após todas as etapas serem concluídas, foi solicitado aos estudantes que descrevessem qual fator alterou a velocidade em cada etapa, se mudou, e o porquê.

A atividade consistiu em um experimento, adaptado de uma atividade disponível no site Ponto Ciência (disponível em: www.pontociencia.org.br), em 
que os estudantes deveriam realizar a mesma reação química, sob alterações de alguns fatores e analisar em quais casos a velocidade da reação é maior, a fim de observarem e discutirem sobre os fenômenos envolvidos. A proposta original apresentada no site citado, consiste em realizar o experimento em potes de filme fotográfico, para os estudantes perceberem em quais situações a tampa é ejetada mais rápido. Em nossa adaptação, deveria ser observado em quais casos a reação se processaria primeiro. $O$ roteiro entregue aos estudantes tem suas etapas apresentadas no Quadro 01.

Quadro 01: Etapas do experimento realizado pelos estudantes

\begin{tabular}{|c|c|}
\hline Etapa & Metodologia \\
\hline 1 & $\begin{array}{l}\text { - Adicione água até aproximadamente, metade do béquer. } \\
\text { - Adicione } 1 / 2 \text { comprimido e observe. }\end{array}$ \\
\hline 2 & $\begin{array}{l}\text { - Adicione a mesma quantidade de água aos dois béqueres. } \\
\text { - Dividir em duas partes um comprimido. } \\
\text { - Triture } 1 / 2 \text { comprimido e deixe a outra metade inteira. } \\
\text { - À um potinho adicione } 1 / 2 \text { comprimido inteiro e ao outro adicione } 1 / 2 \\
\text { comprimido pulverizado. } \\
\text { - Coloque os dois ao mesmo tempo. } \\
\text { - Observe as diferenças. }\end{array}$ \\
\hline 3 & $\begin{array}{l}\text { - Adicione a mesma quantidade de água quente e água fria aos dois } \\
\text { béqueres. } \\
\text { - Adicione } 1 / 2 \text { comprimido efervescente a cada béquer. } \\
\text { - Observe e compare os acontecimentos. }\end{array}$ \\
\hline
\end{tabular}

Fonte: Autoria própria (2017).

c) Etapa 3: Análise dos resultados

A pesquisa tem caráter qualitativo, e os dados obtidos dela foram analisados segundo a Análise de Conteúdo (BARDIN, 1977). A análise se deu em três fases, a saber: pré-análise, exploração do material e tratamento dos resultados. $\mathrm{Na}$ primeira fase, pré-análise, foi feita a leitura flutuante do material que constituiria o corpus de análise a fim de organizá-lo, identificar as unidades de registro e proceder à elaboração dos indicadores. Na fase de exploração do material foi feita a codificação que, por sua vez, se desdobra na organização, contagem e classificação das unidades de registro. Segundo Bardin (1977), essas unidades, na fase de tratamento, são reagrupadas, constituindo categorias que podem se dar $a$ priori ou a posteriori segundo critérios estipulados pelo pesquisador. As categorias podem ser baseadas previamente de acordo com um referencial teórico, categorias a priori; ou podem surgir da análise advinda das informações, denominadas categorias emergentes ou a posteriori (BARDIN, 1977).

Em nosso estudo, fez-se a análise das concepções dos alunos sobre a influência da Temperatura e da Superfície de Contato na alteração da velocidade da reação. Dentro destes dois tópicos, foram separadas categorias a posteriori, referentes às concepções apresentadas acerca destes dois fatores. Assim, o presente trabalho apresenta parte dos resultados. 


\section{RESULTADOS E DISCUSSÃO}

Conforme procedimento descrito anteriormente, a proposta do trabalho constitui em investigar as concepções que os alunos tinham a respeito dos fatores que alteram a velocidade da reação: antes do experimento, verificar o que tinham assimilado após terem estudado de forma teórica o conteúdo com a professora regente da turma; e após o experimento, ver se conseguiam compreender os processos após a observação dos fenômenos. E assim, analisar as concepções deles acerca dos motivos que levam à alteração da velocidade.

Nesse contexto, foi solicitado aos estudantes que identificassem qual fator alterou a velocidade em cada etapa do experimento, justificando o motivo deste fator alterar ou não a velocidade. Desse modo, o corpus de análise da pesquisa foram as respostas dos alunos referentes às questões pré e pós experimento, que foram agrupadas em categorias, contemplando cada tópico abordado. Para esse trabalho tomaremos para discussão somente as categorias relacionadas à influência da Superfície de Contato e da Temperatura.

Nesse cenário, são apresentadas oito categorias, uma a respeito da primeira questão aplicada aos alunos, questão anterior ao experimento. Quatro categorias são sobre a influência da Superfície de Contato, e três que contemplam as concepções acerca do papel da Temperatura na velocidade da reação.

\section{QUESTÃO ANTERIOR AO EXPERIMENTO}

Esta categoria é resultado da análise das respostas à questão número um, respondida antes da atividade experimental, que buscou levantar junto aos alunos quais fatores influenciam a velocidade das reações.

Vale ressaltar que o conteúdo de Cinética Química foi desenvolvido pela professora regente, antes do início do estágio supervisionado. Portanto, esperavase que os alunos soubessem respondê-la. Porém, apesar das respostas dadas pelos estudantes mostrarem que todos sabiam elencar os fatores que alteram a velocidade de uma reação, nenhum aluno justificou. As respostas eram muito semelhantes, como pode ser observado nesses exemplos:

Aluno 12: Catalisadores, temperatura, superfície de contato, pressão, concentração.

Aluno 18: Temperatura, superfície de contato, concentração, pressão, catalisadores.

Aluno 25: Catalisador, temperatura, pressão e superfície de contato. 0 catalisador porque ele altera a rapidez de reação.

Por meio dessas respostas pode se perceber que os estudantes foram capazes de responder, desde que não fosse solicitado a eles que justificassem suas respostas. $\mathrm{O}$ que pode estar associado ao fato de que o contexto em que o conteúdo foi trabalhado inicialmente era de uma aula expositiva com abordagem considerada tradicional, o que forneceu um resultado de aprendizagem mecânica, semelhante ao exposto por Lima et al. (2000) que afirmam que no ensino de Cinética Química: 
[...] as atividades didáticas, muitas vezes, são baseadas em aulas expositivas, que não levam em conta nem os conhecimentos prévios nem o cotidiano dos alunos. Isto torna o ensino deste tópico desmotivante e o discurso do professor é tomado como "dogma de fé" [...] (LIMA et al., 2000, p. 26).

Em contextos como esse, para a avaliação do aprendizado é importante que as perguntas sejam feitas de outras formas, no qual os alunos devam explicar os fenômenos envolvidos. Pois do contrário, as respostas deles irão apenas refletir a memorização e a aprendizagem mecânica de conceitos desconexos de sua realidade.

De acordo com Moreira (2003), ocorre aprendizagem significativa quando o estudante é capaz de fazer relações dos conceitos estudados com o fenômeno, é capaz de argumentar sobre, mostra conhecimento a respeito do termo e pode interagir nas situações utilizando o conhecimento adquirido. Por outro lado, segundo Alegro (2008), a aprendizagem mecânica se dá quando o estudante se apropria de conceitos, por memorização, sem necessariamente saber do que se tratam, utilizando os termos quando são questionados. Muitas vezes essa memorização advém do uso exacerbado do livro didático, ou do discurso do professor (SILVA; SILVA; NETO, 2015), no qual os fatores concentração, temperatura, superfície de contato e presença de catalisadores são continuamente repetidos como sendo os agentes que podem alterar a velocidade das reações.

Podemos inferir então, que no caso aqui analisado houve, inicialmente, aprendizagem mecânica tendo em vista que os alunos responderam da mesma forma mesmo sem saber o significado dos termos citados. A atividade experimental proposta, portanto, foi uma estratégia para tentar fazê-los refletir sobre quais os motivos que levam determinados fatores a alterarem a velocidade das reações.

\section{CONCEPÇÕES SOBRE A INFLUÊNCIA DA SUPERFÍCIE DE CONTATO}

As categorias a seguir são referentes à análise das respostas acerca da etapa do experimento em que foram alteradas as superfícies de contato. Nesta etapa, os estudantes realizaram o experimento em béqueres com mesma quantidade de água, e sob a mesma temperatura, porém, um dos comprimidos foi triturado e o outro não, ambos possuindo a mesma massa.

Foi então solicitado aos estudantes que explicassem esta etapa do experimento, de forma a descrever se houve alteração na velocidade da reação; identificando o fator que estava envolvido em tal variação e o porquê do processo acontecer.

Apenas um estudante não respondeu a esta pergunta, já os demais conseguiram identificar que a alteração ocorrida foi devido a diferença na superfície de contato. Porém, ao justificar o fenômeno ocorreram diversas concepções distintas. Essas concepções foram agrupadas em quatro categorias, que serão descritas a seguir: 
a) Superfície de contato altera a concentração

Sete estudantes justificaram a alteração da velocidade nesta etapa por meio de variação na concentração. Para este grupo, aumentar a superfície de contato aumentaria a concentração. Pode-se inferir que acreditam nisso devido ao fato observável, ou seja, ao observar maior quantidade de pedaços ou partes de comprimido concluem que a concentração é maior. Demonstram-se neste caso, concepções alternativas a respeito do conceito de concentração, afinal estes alunos demonstram acreditar que concentração é proporcional a quantidade, conforme pode ser observado em falas como dos alunos 16 e 20.

Aluno 16: A superfície de contato, porque a concentração do comprimido estava menor pois estava triturado e a reação ocorre mais rápido.

Aluno 20: Superfície de contato, porque a concentração estava menor pois estava triturado e tem mais espaço para ocorrer a reação.

Ou seja, nota-se que na ausência de argumento para explicar o fenômeno, os estudantes recorrem a um conceito já estudado, que está entre os fatores que alteram a velocidade a reação, e pela observação empírica do aumento do número de pedaços de comprimido em solução. Como evidenciado por Mortimer e Miranda (1995), os

[...] estudantes nem sempre reconhecem as entidades que se transformam e as que permanecem constantes, e tendem a centrar suas explicações nas mudanças perceptíveis que ocorrem com as substâncias, sequer fazendo referência às mudanças em nível atômico-molecular (MORTIMER; MIRANDA, p. 23, 1995).

Destaca-se também que ao dizer que a concentração do sistema muda, os estudantes estão transferindo para o nível microscópico os fatos observáveis, ou seja, "[...]aplicam ao nível microscópico o que observam em termos fenomenológicos" (ROSA; SCHNETZLER, 1998, p. 33). Segundo Lopes (1995, apud MACEDO; PENHA, 2014), os estudantes tendem a atribuir mudanças visuais como sendo fenômenos químicos.

A falta de uma demarcação, por parte dos estudantes, entre a observação empírica e o nível de explicação e interpretação das teorias, evidencia a dificuldade desses alunos em entender para que servem os modelos teóricos. Fica evidente a carência de construção de significados para estas teorias, o que pode se tornar obstáculos para a compreensão de conteúdos posteriores (ROSA; SCHNETZLER, 1998), como pode ser observado nesta categoria, onde a não compreensão do conceito de Concentração levou os alunos a uma interpretação ineficaz da alteração da velocidade de reação por modificação na superfície de contato.

b) Maior área de contato é equivalente a espaço ocupado pelo reagente

Nesta categoria estão incluídas duas respostas, as quais baseiam-se na observação de que há mais espaço para a reação ocorrer. Percebe-se que ao relatar alteração de espaço eles tentavam se referir a existir maior contato da água com o comprimido, porém não souberam utilizar os termos adequados para descrever o que foi observado. Como pode-se ver nas seguintes falas: 
Aluno 01: Na etapa 2 o que mudou foi a superfície de contato, o [comprimido] em pedaços é mais rápido, porque ocupa um espaço maior.

Aluno 25: A superfície de contato: porque é maior o espaço e terá um efeito mais rápido e passará mais rápido.

Provavelmente estes estudantes atribuem a maior quantidade de pedaços de comprimido, a um maior espaço físico para a ocorrência da reação química, o que mostra novamente, o fato de basearem-se apenas nas observações empíricas e no mundo macroscópico.

O ensino de cinética Química no ensino médio baseia-se tanto em termos de nível macroscópico quanto em microscópico. De acordo com Kotz, Treichel e Weaver (2013, apud ZAPPE; SAUERWEIN, 2016), os conceitos em nível macroscópico estão ligados ao conceito de velocidade da reação e sua determinação experimental, além dos fatores que alteram a velocidade. Os termos de nível microscópico incluem o processo envolvido nestas reações, ou seja, os caminhos percorridos por átomos e moléculas durante o processo.

Abordagens demasiadamente expositivas não são capazes de oportunizar a construção destes conceitos, de relacionar aspectos microscópicos com os fatos observados, devido ao grau de abstração necessário, o que recomenda a utilização de estratégias didáticas que possam auxiliar no processo de ensino e aprendizagem. Ao identificar dificuldades em argumentar e compreender o fenômeno, como evidenciado nesta categoria, pode-se traçar estratégias como por exemplo, utilizar uma abordagem contextualizada para o ensino de cinética química (LIMA et al., 2000).

c) Superfície de Contato é um catalisador

Três estudantes atribuíram à alteração de superfície de contato a característica de catalisador, demonstrando que acredita que o conceito de catalisador se refere a qualquer fator que eleve a velocidade da reação:

Aluno 08: Na etapa no 2 foi a superfície de contato, porque elas são catalisadores, ela se desmancha mais rápido por causa do tamanho do comprimido.

Nota-se nessa fala que o estudante não compreende o conceito adequado do que seja um catalisador, e nem do que é a alteração na superfície de contato. Dessa forma, o termo catalisador é utilizado como um adjetivo, ou uma classe de fatores que alteram a velocidade da reação. Percebe-se novamente, como a má interpretação de um conceito pode gerar um equívoco ao explicar outros conceitos ou fenômenos. Ao não compreender o significado do conceito de catalisador, o estudante não consegue explicar os outros fatores relacionados à velocidade, sem relacioná-los ao termo catalisador. Uma nova discussão a respeito do catalisador é apresentada mais adiante, em uma das categorias referentes a temperatura, onde concepção semelhante foi identificada. 
d) Não justifica a influência da superfície de contato

Como mencionado anteriormente, foi possível notar nas respostas dadas pelos estudantes certa dificuldade em relacionar os fatos observados com os modelos teóricos, visto que eles não estão habituados a justificar suas respostas, e quando são convidados a refletir sobre os conceitos, demonstram dificuldades em argumentar. Treze alunos identificaram que houve alteração de superfície de contato, porém não apresentaram justificativa. Tal ocorrência pode ser observada nas falas dos alunos 04 e 10 :

Aluno 04: Na etapa 2 a superfície de contato acelerou a velocidade, o que aconteceu mais rápido a reação foi o triturado, por causa da superfície de contato.

Aluno 10: Na etapa 2 uma metade do comprimido foi triturado e a outra metade inteira, a metade triturada reagiu mais rápido e a mudança foi a superfície de contato.

Das respostas desses estudantes, nota-se que, apesar de conseguirem identificar que o fator responsável pela alteração de velocidade foi a superfície de contato, existe uma falta de argumentos que sustentem as afirmações feitas por eles. Tal lacuna é consequência de um modelo de ensino baseado somente na memorização de fórmulas e conceitos, defasando a aprendizagem à medida que não propicia espaço para reflexões, nem contribui para o desenvolvimento da escrita, interpretação e da argumentação tão necessários à construção de novos conhecimentos.

\section{CONCEPÇÕES SOBRE A INFLUÊNCIA DA TEMPERATURA}

As categorias a seguir são referentes a análise das respostas acerca da etapa do experimento em que foi alterada a temperatura do sistema. Nesta etapa, os estudantes realizaram o experimento em béqueres com mesma quantidade de água, mas com temperaturas diferentes em cada um deles, utilizando comprimidos de mesma massa.

Assim como na etapa anterior, foi solicitado aos alunos que explicassem esta etapa do experimento, de forma a descrever se houve alteração na velocidade da reação; identificando o fator que estava envolvido em tal variação, e o porquê de o processo acontecer. Todos os estudantes identificaram que o fator alterado nesta etapa foi a temperatura, e boa parte tentou explicá-la fazendo com que houvesse um maior número de respostas distintas. Dessas respostas emergiram três categorias como se segue. Seis alunos não justificaram, portanto não demonstraram suas concepções a respeito da influência da temperatura, de acordo com a discussão da categoria $d$ sobre a superfície de contato.

\section{a) Atribuem à Temperatura a definição de catalisador}

Essa primeira categoria compreende as respostas de dois alunos, em que os estudantes justificam o aumento da velocidade pelo aumento de temperatura, alegando que a temperatura é um catalisador. Novamente percebe-se que alguns 
estudantes não compreenderam o que é um catalisador, e atribuem a qualquer fator capaz de elevar a velocidade de uma reação química o adjetivo de catalisador.

Percebe-se então uma possível falha no momento de sistematizar este conhecimento no processo de ensino, onde muitas vezes o próprio livro didático diz apenas que os catalisadores são um fator que aumenta a velocidade das reações, e o professor acaba por perpetuar estes conceitos (SILVA; SILVA; NETO, 2015). Nesse sentido, é importante estar atento às concepções apresentadas pelos estudantes a respeito do conceito em estudo.

Vejamos então algumas falas que estão contidas nesta categoria:

Aluno 07: A temperatura da água ela funciona como catalisador. Porque aumenta a energia cinética porque aumenta.

Aluno 06: A temperatura mais alta funciona como catalisador, porque aumenta a energia cinética que é a molécula dos movimentos. A água quente absorve mais rápido do que a água gelada.

Fica claro, ao observar estas respostas, que os estudantes conseguem fazer ligação entre as questões do aumento de energia cinética devido a temperatura da água. Porém, ao não compreender a definição de catalisador, utilizam o termo fora do contexto, ao tentar explicar por que a temperatura aumenta a velocidade da reação, apesar de mencionar o aumento da energia das moléculas.

O aluno 06 ainda demonstra não ter compreendido o termo energia cinética, e nota-se dificuldade em caracterizar o que seja uma molécula, o que fica claro ao dizer que "a energia cinética é a molécula dos movimentos". Nota-se, portanto, dificuldades em sistematizar estes conceitos fundamentais da Química, e como eles interferem na aprendizagem de outros conteúdos, neste caso a compreensão do conteúdo de Cinética Química.

b) Energia cinética, agitação das moléculas e colisões efetivas sem relação entre os termos

A segunda categoria é composta pelas respostas de quinze estudantes, que utilizaram os termos energia cinética, agitação das moléculas e/ou colisões efetivas. Quatorze alunos utilizaram os termos de forma isolada. Neste caso, não utilizaram todos os termos juntos para justificar o motivo do aumento de temperatura, mas utilizaram termos isolados para explicar o ocorrido, como pode ser observado nas seguintes falas:

Aluno 01: Na outra foi água quente a água fria, a quente foi mais rápida porque aumenta a energia cinética;

Aluno 02: Eu entendi que conforme a temperatura ela agita as moléculas elas se aceleram;

Aluno 10: Na etapa 3 mudamos a temperatura da água, e a com maior temperatura reagiu mais rápido, a maior temperatura aumenta a energia cinética; 
Nota-se nestas falas que os estudantes utilizaram estes termos de forma isolada, como se não precisassem estar juntos para justificar o fenômeno. Por exemplo, quando os alunos 01 e 10 dizem que a reação foi mais rápida porque aumentou a energia cinética, suas respostas estão corretas, porém eles não deixam claro se sabem o que é a energia cinética, ou de que forma ela está relacionada ao aumento de temperatura.

Já na fala do aluno 12 , ele deixa claro que compreende que as moléculas são aceleradas com o aumento da temperatura, mas não menciona que a energia cinética, que é a energia de movimento, é aumentada devido a este fato, nem que ocorre o consequente aumento do número de colisões efetivas.

Nota-se nestas falas que os estudantes acreditam que apenas um dos termos (energia cinética, agitação das moléculas ou colisões efetivas) seriam suficientes para explicar o fenômeno.

Por outro lado, nas falas dos alunos 08 e 21 pode ser percebida a compreensão dos conceitos, visto que são trazidas algumas justificativas:

Aluno 08: Aumenta a energia cinética que é a energia de movimento.

Apesar de ser uma fala curta e precisa, podemos interpretar que o aumento de temperatura ocorreu devido ao aumento de energia cinética, que é a energia de movimento. Somente este aluno explicou o significado do termo energia cinética ao utilizá-lo.

Aluno 21: Temperatura. Temperatura mais alta aumenta a movimentação das moléculas, que eleva a quantidade de colisões. [...] $O$ aumento da temperatura aumentou a movimentação das moléculas, assim fazendo com que ele se dissolva mais rápido.

O aluno 21 foi o autor da única resposta que atribuiu o aumento de temperatura à movimentação das moléculas, que leva ao maior número de colisões efetivas.

É importante mencionar que a não familiarização dos estudantes com o termo colisões efetivas pode ser atribuída ao fato de que os livros didáticos não trazem este conceito de forma clara, e consequentemente a maioria dos professores não se aprofunda neles. Como visto no trabalho de Cirino e Souza (2010), os aspectos probabilísticos das colisões entre as moléculas não são explorados na maioria dos livros didáticos. Ou seja, a forma que as partículas se movimentam, e o caráter aleatório do choque entre elas não fica claro segundo a abordagem de muitos livros. Além disso, o estudo da Cinética Química não é relacionado a outros conceitos, como por exemplo a Termoquímica. Nota-se também que:

\footnotetext{
Há pouco destaque, nesses livros, sobre a grande diferença entre a cinética e a termodinâmica química: a velocidade de uma reação química depende do mecanismo da reação, enquanto que a quantidade de energia (calor) liberada ou absorvida por uma reação química depende apenas da natureza dos reagentes e dos produtos formados, isto é, independe do mecanismo de como os reagentes se transformaram em produtos. (CIRINO; SOUZA, p. 135, 2010).
}

Ou seja, além dos aspectos superficiais, ainda há falta de ligação entre os conteúdos, o que torna a química ainda mais abstrata e fragmentada, o que pode trazer obstáculos para compreensão dos conceitos por parte do estudante. 
A respeito do termo Energia Cinética, houve um aluno que o utilizou de forma inadequada, mostrando que não compreendeu seu significado, conforme pode ser observado em sua fala:

Aluno 11: Alterou, pois, a água estava com a cinética por causa que o comprimido na água quente dissolve mais rápido.

Ao observarmos estas falas, podemos inferir então que os estudantes tiveram dificuldades em relacionar estes termos ao aumento da temperatura e, portanto, apresentam certa dificuldade em explicar seus significados.

c) Aumento da Temperatura pela quantidade de produto liberado

Nessa categoria foram contempladas três respostas, que tem a base de suas justificativas no fato de poderem observar formação de produto, tal como ilustrado na seguinte fala:

Aluno 11: Na etapa 3 foi com a água quente e fria, na água quente o comprimido liberou mais gás.

Esse caso é semelhante ao que já foi anteriormente discutido, no qual os alunos atribuem a ocorrência de uma reação química àquilo que podem ver. Esse é um ponto delicado e importante de ser discutido visto que as respostas dos alunos, nas diferentes categorias apresentadas, evidenciaram que os alunos possuem dificuldade em compreender também o conceito de reação química. Justi e Ruas (1997) descrevem em seu trabalho a influência da concepção de transformação da matéria na aprendizagem do conteúdo de cinética Química, e entre outras colocações destacam a importância de compreender os conceitos de reação química.

Ademais, nota-se novamente o que foi discutido por Mortimer e Miranda (1995) e por Rosa e Schnetzler (1998) sobre as dificuldades de os estudantes explicarem fenômenos além do campo visual, ou de utilizá-los para explicar a teoria. Os estudantes acabam por fazer a associação de que ocorre reação química quando é produzido algo, seja durante a reação ou como um produto, que possa ser visto. $\mathrm{O}$ aluno 11 , por exemplo, chega à conclusão de que a temperatura aumentou a velocidade da reação, porque houve mais formação de gás (produto).

\section{CONSIDERAÇÕES FINAIS}

Diante das categorias de análise apresentadas, reforça-se a hipótese inicial de que as respostas dadas pelos alunos à questão número um, questão anterior ao experimento, eram semelhantes em consequência da memorização e da aprendizagem mecânica, pois os estudantes não haviam compreendido os significados dos termos que estavam utilizando. Após a realização do experimento, a maioria passa a justificar o fenômeno por meio da observação empírica, mostrando dificuldades em relacioná-lo ao modelo teórico. Ficou evidente nas respostas dadas pelos alunos a existência de certas concepções, e más 
para a compreensão do fenômeno em estudo, já que as respostas se basearam majoritariamente apenas nos fatos observáveis.

Por outro lado, alguns estudantes mostraram compreender os conceitos e conseguiram relacioná-los aos fatos observados, porém apresentaram dificuldade em tecer argumentos para sustentar suas respostas. Assim, foi observável a carência de práticas de ensino que estimulem o desenvolvimento da linguagem escrita e da argumentação nos alunos; além da falta de apropriação de conceitos químicos base para compreensão do conteúdo de cinética, como por exemplo o conceito de reação química, que muitos estudantes mostraram não compreender, quando utilizam os termos dissolução e absorção para se referirem a reação. Ou quando o termo catalisador é empregado como adjetivo para qualquer fator que altere a velocidade, o que mostra concepções alternativas a respeito do conceito de catalisador, levando-os a uma interpretação equivocada do fenômeno em questão.

Não foram encontrados na literatura trabalhos que discorrem acerca das concepções de estudantes, especificamente relacionadas à influência da temperatura e da superfície de contato, não sendo possível fundamentar as categorias de análise em categorias de trabalhos preexistentes. Foi possível somente relacioná-las com trabalhos que envolvessem os conceitos ao qual estavam relacionadas.

Nesse sentido, infere-se a importância de conhecer as ideias prévias e as concepções dos estudantes sobre o conteúdo em discussão, pois conhecendo suas dificuldades e padrões, podemos investigar novas estratégias que possibilitem a melhoria da prática docente, visando a aprendizagem significativa e consequentemente a melhoria do Ensino de Química. 


\title{
Concepts about Chemical Kinetics: the influence of Temperature and Surface Contact
}

\begin{abstract}
Identifying the students' conceptions is fundamental for the teaching and learning processes, because by knowing them it is possible to plan and organize the activities to be developed with the students. Given this, we present here part of the results of a research that aimed to analyze the conceptions of high school students about the factors that alter the speed of chemical reactions, specifically discussing the conceptions about the influence of contact surface and temperature. The research was carried out with 26 students of the second year of high school of a public school in Paraná. The data were collected through the researcher's field diary and questionnaires, regarding the accomplishment of an experiment. The data were analyzed according to the Bardin Content Analysis. The answers were grouped in eight categories, which revealed empirical descriptions, in which it was possible to observe that the students present difficulties in relating the practice observed in the experiment with the content learned in the classroom, besides evidencing difficulties of argumentation and writing. Mechanical learning has become evident, which leads students to memorize the factors that alter the speed of reactions without a true understanding of the content. Most students have difficulty in relating kinetic energy and effective collisions, and it is difficult to justify the influence of the contact surface. By knowing the students' difficulties, it is possible to draw up adequate didactic strategies to improve learning.
\end{abstract}

KEYWORDS: Alternative conceptions. Chemistry teaching. Contact Surface. Temperature. 


\section{REFERÊNCIAS}

BARDIN, L. Análise de conteúdo. Lisboa: Edições 70, 1977.

BEHRENS, M. A. O paradigma emergente e a prática pedagógica. 6a ed. Petrópolis: Vozes, 2013.

CIRINO, M. M.; SOUZA, A. R. O tratamento probabilístico da Teoria Cinética de Colisões em livros de Química brasileiros para o Ensino Médio. Revista Electrónica de Enseñanza de las Ciencias, v. 9, n. 1, p. 125-144, 2010. Disponível em: <http://reec.uvigo.es/volumenes/volumen9/ART8_VOL9_N1.pdf>. Acesso em: 20mai. 2017.

COSTA, T. S.; ORNELAS, D. L.; GUIMARÃES, P. I. C.; MERÇON, F. Experimento com alumínio. Química Nova na Escola, n. 23, p. 38-40, 2006. Disponível em: <http://qnesc.sbq.org.br/online/qnesc23/a09.pdf>. Acesso em: 20 mai. 2017.

FRANCISCO JUNIOR, W. E. Estratégias de leitura e educação química: Qual relação? Química Nova na Escola, v. 32, n. 4, p. 220-226, 2010. Disponível em: <http://qnesc.sbq.org.br/online/qnesc32_4/03-EA5809.pdf>. Acesso em: 20 mai. 2017.

GIORGI, S.; CONCARI, S.; POZZO, R. Un estudio sobre las investigaciones acerca de las ideas de los estudiantes en fuerza y movimiento. Ciência \& Educação, v. 11, n. 1, p. 83-95, 2005. Disponível em:

<http://www.scielo.br/pdf/ciedu/v11n1/08.pdf>. Acesso em: 20 mai. 2017.

GOMES, L. C. Concepções alternativas e divulgação: análise da relação entre força e movimento em uma revista de popularização científica. Dissertação (Mestrado em Educação para a Ciência e a Matemática), Universidade Estadual de Maringá, Maringá, 2008. Disponível em:

<http://www.pcm.uem.br/uploads/2008-luciano-carvalhaisgomes_1434077778.pdf.>. Acesso em: 20 mai. 2017.

HÜLSENDEGER, M. J. V. C. Compreendendo a importância de saber o que o aluno sabe. Revista Espaço Acadêmico, n. 99, p. 20-22, Vitória-ES, 2009. Disponível em: <http://www.periodicos.uem.br/ojs/index.php/EspacoAcademico/article/view/7 661/4445>. Acesso em: 20 mai. 2017. isolados de conhecimento? Química Nova na Escola, n. 5, p. 24- 27, 1997. Disponível em: <http://qnesc.sbq.org.br/online/qnesc05/pesquisa.pdf>. Acesso em: 30 abr. 2017. 
LIMA, J. F. L.; PINA, M. S. L.; BARBOSA, R. M. N.; JÓFILI, Z. M. S. A contextualização no ensino de cinética química. Química Nova na Escola, n. 11, p. 26-29, 2000. Disponível em: <http://qnesc.sbq.org.br/online/qnesc11/v11a06.pdf>. Acesso em: 30 abr. 2017.

LOPES, A. R. C. Bachelard: O filósofo da desilusão. Caderno Brasileiro de Ensino de Física, v. 13, n. 3, p. 248-273, Joinville-SC, 1996. Disponível em: $<$ http://www.joinville.udesc.br/portal/professores/susana/materiais/Bachelard.p df>. Acesso em: 20 mai. 2017.

MACEDO, J. M.; PENHA, M. R. Desmistificando a Química: investigação das definições do IFRO sobre o real conceito das Reações Químicas. Educação Por Escrito, v. 5, n. 1, p. 51-67, Porto Alegre, 2014. Disponível em: <http://revistaseletronicas.pucrs.br/ojs/index.php/porescrito/article/viewFile/15 818/11500>. Acesso em: 20 mai. 2017.

MENDES, H. M. A.; CARDOSO, S. P. Análise das concepções prévias dos alunos do 10 ano do Ensino Médio da rede pública acerca do meio ambiente e política.

Anais. VII Encontro Nacional de Pesquisa em Educação em Ciências. Florianópolis, 2009.

MERÇON, F.; GUIMARÃES, P. I. C.; MAINIER, F. B. Sistemas experimentais para o estudo da corrosão em metais. Química Nova na Escola, v. 33, n. 1, p. 57-60, 2011. Disponível em: <http://qnesc.sbq.org.br/online/qnesc33_1/08EEQ6810.pdf>. Acesso em: 20 mai. 2017.

MOREIRA, M. A. ¿Al afinal, qué es aprendizaje significativo? Revista Qurriculum, n. 25, La Laguna-Espanha, p. 29-56, 2012. Disponível em: <http://www.lume.ufrgs.br/handle/10183/96956 >. Acesso em: 20 mai. 2017.

MOREIRA, M. A. Linguagem e aprendizagem significativa. Anais. IV Encontro Internacional sobre Aprendizagem Significativa, Maragogi-AL, 2003. Disponível em: <https://www.if.ufrgs.br/ moreira/linguagem.pdf>. Acesso em: 20 mai. 2017.

MOREIRA, M. A. Comportamentalismo, construtivismo e humanismo. Coletânea Subsídios teóricos para o professor pesquisador em ensino de ciências. 2 ed. Porto Alegre, 2016. Disponível em: <https://www.if.ufrgs.br/ moreira/Subsidios5.pdf>. Acesso em 20 jun. 2017.

MORTIMER, E. F.; MIRANDA, L. C. Concepções de estudantes sobre Reações Químicas. Química Nova na Escola, n. 2, p. 23-26, 1995. Disponível em: 
PEREIRA, A. P. Um panorama da pesquisa internacional sobre mudança conceitual. Revista brasileira de pesquisa em educação em ciências, v. 17, n. 1, p.215-242, 2017. Disponível em: <https://seer.ufmg.br/index.php/rbpec/article/viewFile/2746/3250>. Acesso em 20 jun. 2017.

ROCHA-FILHO, R. C. Femtoquímica: reações químicas em tempo real. Química Nova na Escola, n. 10, p. 14-16, 1999. Disponível em: <http://qnesc.sbq.org.br/online/qnesc10/atual2.pdf>. Acesso em: 20 jun. 2017.

ROSA, M. I. F. P. S.; SCHNETZLER, R. P. Sobre a importância do conceito transformação química no processo de aquisição do conhecimento químico. Química Nova na Escola, n. 8, p. 31-35, 1998. Disponível em: <http://www.contagem.mg.gov.br/arquivos/comunicacao/femcitec_sobreoconc eitodatransformacao09.pdf>. Acesso em: 20 jun. 2017.

SANTOS, W. L. P.; SCHNETZLER, R. P. Educação em química: compromisso com a cidadania. - 4ed: Ed. Unijuí. ljuí, 2010.

SCHNETZLER, R. P. A pesquisa no ensino de Química e a importância da Química nova na Escola. Química Nova na Escola, n. 20, p. 49-54, 2004. Disponível em: <http://qnesc.sbq.org.br/online/qnesc20/v20a09.pdf>. Acesso em: 20 mai. 2017.

SCHNETZLER, R. P.; ARAGÃO, R. M. R. Importância, sentido e contribuições de pesquisas para o Ensino de Química. Química Nova na Escola, n. 1, p. 27-31, 1995. Disponível em: <http://qnesc.sbq.org.br/online/qnesc01/pesquisa.pdf>. Acesso em: 20 jun. 2017.

SILVA, P. N.; SILVA, F. C. V.; NETO, J. E. S. A Transposição Didática do Conteúdo de Cinética Química: Do Saber Científico ao Saber Ensinado. Anais: X Encontro Nacional de Pesquisa em Educação em Ciências. Águas de Lindóia, 2015. Disponível em: <http://www.abrapecnet.org.br/enpec/xenpec/anais2015/resumos/R0194-1.PDF>. Acesso em 30 abr. 2017.

TEÓFILO, R. F.; BRAATHEN, P. C.; RUBINGER, M. M. M. Reação relógio iodeto/ iodo com material alternativo de baixo custo e fácil aquisição. Química Nova na Escola, n. 16, p. 41-44, 2002. Disponível em: <http://qnesc.sbq.org.br/online/qnesc16/v16_A10.pdf>. Acesso em: 30 abr. 2017.

VENQUIARUTO, L. D.; DALLAGO, R. M.; VANZETO, J.; DEL PINO, J. C. Saberes populares fazendo-se saberes escolares: um estudo envolvendo a produção artesanal de pão. Química Nova na Escola, v. 33, n. 3, p. 135-141, 2011. Disponível em: 
<http://www.educadores.diaadia.pr.gov.br/arquivos/File/outubro2011/quimica_ artigos/saber_pop_escolar_art.pdf>. Acesso em: 20 jun. 2017.

ZAPPE, J. A.; SAUERWEIN, I. P. S. O ensino de Cinética Química nos periódicos nacionais. Anais: XVIII Encontro Nacional de Ensino de Química, Florianópolis-SC, 2016. Disponível em: <http://www.eneq2016.ufsc.br/anais/resumos/R13851.pdf>. Acesso em: 30 abr 2017.

Recebido: 29 mai. 2017

Aprovado: 21 ago. 2017

DOI: $10.3895 /$ actio.v2n1.6777

Como citar:

MARANI, P. F.; OLIVEIRA, T. A. L. de; SÁ, M. B. Z. Concepções sobre Cinética Química: a influência da

Temperatura e da Superfície de Contato. ACTIO, Curitiba, v. 2, n. 1, p. 321-341, jan./jul. 2017. Disponível em: <https://periodicos.utfpr.edu.br/actio>. Acesso em: XXX.

Correspondência:

Pamela Franco Marani

Rua Pioneiro Ercílio Silva, n 336, Conj. Guaiapó. Maringá-PR, Brasil.

Direito autoral: Este artigo está licenciado sob os termos da Licença CreativeCommons-Atribuição 4.0

Internacional.

(c) (1) 